\title{
EVALUATION OF THE HEALTH-RELATED QUALITY OF LIFE IN ELDERLY PATIENTS ACCORDING TO THE TYPE OF HIP FRACTURE: FEMORAL NECK OR TROCHANTERIC
}

\author{
Tânia Maria da Silva Mendonça, ${ }^{I}$ Carlos Henrique Martins da Silva, ${ }^{I}$ Roberto \\ Sérgio de Tavares Canto, ${ }^{\mathrm{II}}$ Nívea de Macedo Oliveira Morales, ${ }^{\mathrm{I}, \mathrm{III}}$ Rogério de \\ Melo Costa Pinto, ${ }^{\mathrm{IIV}}$ Rogério de Rizo Morales ${ }^{\mathrm{I}, \mathrm{III}}$
}

doi: 10.1590/S1807-59322008000500007

Mendonça TMS, Silva CHM, Morales NMO, Morales RR, Canto RST, Pinto RMC. Evaluation of the health-related quality of life in elderly patients according to the type of hip fracture: femoral neck or trochanteric. Clinics. 2008;63(5):607-12.

OBJECTIVE: To evaluate the effect the type of hip fracture (femoral neck or trochanteric) has on the Health-Related Quality of Life of elderly subjects.

METHODS: Forty-five patients with hip fractures (mean $74.30 \pm 7.12$ years), 24 with a femoral neck fracture and 21 with a trochanteric fracture, completed the 36-item Short Form Health Survey (SF-36) at baseline and four months after fracture. The Health-Related Quality of Life scores were compared according to fracture type, undisplaced and displaced femoral neck fractures, and stable and unstable trochanteric fractures.

RESULTS: Compared to baseline, all patients scored lower in the physical functioning, role limitation-physical, bodily pain and vitality categories four months after the fracture had occurred. The SF-36 scores for all the scales did not differ significantly between patients with femoral neck versus trochanteric fractures, or between patients with displaced versus undisplaced femoral neck fractures and stable versus unstable trochanteric fractures.

CONCLUSIONS: The mental and physical quality of life of elderly patients with a hip fracture is severely impaired one month after fracture, with partial recovery by the end of the fourth month. The negative impact on the Health-Related Quality of Life did not differ significantly according to fracture type.

KEYWORDS: Elderly; Falls; Health-Related Quality of Life; Hip fracture; SF-36.

\section{INTRODUCTION}

Hip fractures are recognized as one of most serious consequences of osteoporosis, and their incidence has been used as an international index of the frequency of osteoporosis. ${ }^{1}$ Most hip fractures occur after falls, and are

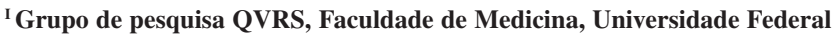
de Uberlândia - Uberlândia/ MG, Brazil.

II Serviço de Ortopedia e Traumatologia, Faculdade de Medicina, Universidade Federal de Uberlândia - Uberlândia/ MG, Brazil.

III Neurology Discipline, Faculdade de Medicina, Universidade Federal de Uberlândia - Uberlândia/ MG, Brazil.

Iv Faculdade de Matemática, Universidade Federal de Uberlândia - Uberlândia/ MG, Brazil.

Phone: 5534 3235.1514

Email: tânia_fisio@hotmail.com

Received for publication on June 20, 2008.

Accepted for publication on June 26, 2008.
}

a considerable burden to the health care system through their association with increased mortality and morbidity. ${ }^{2,3}$ In Brazil, around 100,000 hip fractures occur annually according data from DATASUS, a Brazilian public health service. The global senior-citizen population that has experienced a hip fracture is set to reach 6.3 million in $2050 .^{2,4}$ Hip fractures will then be one of the greatest challenges for society and health systems. ${ }^{2,3}$

Elderly patients' recovery after hip fracture is traditionally evaluated by the presence of surgical complications, ${ }^{5}$ and by the magnitude of functional limitations. ${ }^{5-8}$ The proportion of elderly people who experience immobility or functional dependency to accomplish the activities of daily life rises over a period of one to two years after the hip fracture. ${ }^{9}$

Recently, there has been growing interest in investigating the effects of hip fractures and their treatment on the quality 
of life as perceived by the elderly patient, because knowing which aspects are the most compromised could improve health care interventions and public resource allocation. ${ }^{10}$ The assessment of the Health-Related Quality of Life (HRQOL) can also complement conventional outcome measures. ${ }^{11}$

Studies have shown an impairment in the quality of life in elderly subjects with a hip fracture in both the physical and psychosocial domains. ${ }^{4,8-16}$ HRQOL in elderly people suffering hip fractures has been evaluated at different time points during rehabilitation, and a considerable decline in HRQOL is shown during the initial phase after fracture. ${ }^{8-16}$ Between the third and fourth months after the fracture, partial recovery is observed in the physical and psychosocial factors. ${ }^{9-14,17,18}$ However, these physical and psychosocial aspects do not fully recover, thereby perpetuating the negative effects of hip fracture on the HRQOL. ${ }^{8-13,15-16,19-21}$

Although there are substantial differences in the pathogenesis between femoral neck and trochanteric hip fractures, studies that have previously investigated the prognostic role of the hip type fracture in functional recovery have produced conflicting results. ${ }^{22-24}$ Moreover; possible differences in elderly patients' quality of life according to the type of hip fracture have not been assessed.

The aim of this study was to determine the impact of hip fractures on HRQOL in the Brazilian elderly population, and to ascertain whether there are differences in the HRQOL according to the type of fracture.

\section{METHODS}

\section{Study design and patients}

Between June 2005 and January 2006, patients admitted for hip fracture to a university hospital in Uberlândia, Brazil were recruited for this study. The inclusion criteria were: aged 60 years or older, hospitalization due to hip fracture, surgery for either internal fixation or arthroplasty, absence of cognitive dysfunction (assessed by applying the mini-mental state examination), independent living (not institutionalized), and hindered walking capability before the fracture. Patients with major trauma, malignancy and rheumatoid arthritis, and other causes of pathologic fractures were excluded. The study was approved by the local research ethics committee, and written informed consent was obtained.

\section{Procedures}

The same investigator interviewed and evaluated all patients using a standard protocol within 48 hours after surgery. Social, demographic and residence data were obtained. The type of fracture was analyzed and recorded as a femoral neck fracture or a trochanteric fracture. Femoral neck fractures were classified as undisplaced (Garden I and II), or displaced (Garden III or IV), and trochanteric fractures as stable or unstable.

Cognitive status was assessed by applying the minimental state examination, which results in a score between zero and $30 .{ }^{25}$ Only patients with scores of 22 or above were included in the study.

The SF-36 was applied to the patient group within 48 hours after surgery (baseline data) and four months after admission to hospital, using a face-to-face interview.

\section{Assessment of quality of life}

HRQOL was measured using the Brazilian version of the 36-item Short Form Health Survey (SF-36). ${ }^{26}$ The SF-36 is a generic quality of life instrument, which contains 36 items that measure eight physical and mental dimensions of health: "physical functioning", "role limitations due to physical functioning”, "bodily pain”, "general health", "role limitations due to emotional problems", "vitality", "mental health", and "social functioning". Scores on each scale range from 0 to 100 . A score of 100 indicates the highest health rating. The internal consistency reliability of the SF-36 was verified.

\section{Statistical methods}

The sociodemographic and clinical features of the patients were recorded through descriptive statistical analysis. Pearson's chi-square test was used to compare the number of years of education and family income for the patient group according to the type of fracture.

The HRQOL was analyzed by the Friedman test ant then, with Dunn's post-hoc test considering dependence relationships among baseline and the first and fourth months, without taking the type of fracture into account. The MannWhitney test was used to compare the HRQOL among patients with femoral neck fractures (unsdisplaced versus displaced) and patients with trochanteric fractures (stable versus unstable) at baseline and at the fourth month after surgery.

The independent-samples t test was used to compare the HRQOL among the patients with femoral neck and trochanteric fractures at baseline and at the fourth month after the fracture.

The reliability of the internal consistency of SF-36 was calculated for each domain using Cronbach's alpha coefficient. Values above 0.7 in the group comparison were considered as adequate. ${ }^{27}$ 


\section{RESULTS}

Of the 80 patients hospitalized for hip fracture during the study period, 12 (15\%) died and 23 (28.7\%) exhibited cognitive dysfunction (mini-mental state examination score lower than 22). Thus, the final sample consisted of 45 elderly patients aged with mean $74.3 \pm 7.12$ years $(62-92)$ at the time of fracture. Of the patients, $60 \%$ were female and $40 \%$ were male. Eighteen (40\%) had no formal education. With regard to the fracture type, $24(53.3 \%)$ were diagnosed as having a FNF (femoral neck fracture), and $21(46.7 \%)$ as having a TF (trochanteric fracture) (Table 1).

There were no significant differences in the demographic or clinical characteristics of patients with FNF versus those with TF by Pearson's chi-square test. All of the patients were submitted to surgery $2.1 \pm 0.7$ days after the hip fracture. Of the $24(53.3 \%)$ subjects with FNF, 14 (31.1\%) had received internal fixation, and 10 (22.2\%) received arthroplasty. The average length of the hospital stay was $10.1 \pm 5.26$ days for the FNF patients and $11.7 \pm 7.87$ days for the TF patients. The mean number of medications taken daily was $3.7 \pm 1.06$, and $64.4 \%$ of the patients had reported at least one fall over the past year.

The internal consistency reliability for all the SF-36 scales was adequate and Cronbach's alpha coefficient ranged from 0.70 to 0.91 .

Compared to the baseline, patients had a significantly lower score in the physical functioning, role limitationphysical, bodily pain and vitality categories at four months after fracture (Table 2).

The HRQOL according to the SF-36 for FNF and TF at baseline and four months after discharge from hospital are presented in Table 3. Compared to the baseline, the scores for all the SF-36 scales did not differ at four months after discharge. Patients with a displaced FNF had a similar quality of life to those with an undisplaced FNF at
Table 1 - Sample characteristics of 45 patients with hip fractures

\begin{tabular}{ll}
\hline Characteristics & Patients \\
\hline Age: average (SD) & $74.38(7.12)$ \\
Hip fracture type & \\
Femoral neck fracture (n) & 24 \\
$\quad$ Garden (I and II) & 14 \\
$\quad$ Garden (III and IV) & 10 \\
Trochanteric fracture (n) & 21 \\
$\quad$ Stable & 12 \\
$\quad$ Unstable & 9 \\
Years of education: $\mathrm{n}(\%)$ & \\
Illiterate & $18(40)$ \\
1 to 4 years & $6(13.3)$ \\
5 to 8 years & $16(35.6)$ \\
9 to 11 years & $4(8.9)$ \\
$>$ 11 years & $1(2.2)$ \\
Cohabitation: $\mathrm{n}(\%)$ & \\
Family & $28(62.2)$ \\
Alone & $17(37.8)$ \\
Retired: $\mathrm{n}(\%$.) & $34(75.6)$ \\
\hline
\end{tabular}

baseline (Table 4). Patients with a displaced FNF differed significantly from those with an undisplaced FNF at four months after discharge only in one mental-related scale (vitality) (Table 4). Of the patients with TF, there were no significant differences between the means of both physical and mental-related scales before the fracture and at the four month follow-up (Table 5).

\section{DISCUSSION}

The current paper focuses on the effect that the types

Table 2 - SF-36 scores (median and percentiles) in patients with hip fractures at baseline, one month and four month follow-up

\begin{tabular}{|c|c|c|c|}
\hline Scales & Baseline median (25th / 75th) & One month median (25th / 75th) & Four month median (25th / 75th) \\
\hline Physical functioning & $65^{\mathrm{a}}(37 / 85)$ & $0^{\mathrm{b}}(0 / 0)$ & $51^{\mathrm{c}}(45 / 56)$ \\
\hline Role limitation - physical & $50^{\mathrm{a}}(0 / 100)$ & $0^{\mathrm{b}}(0 / 0)$ & $20^{\mathrm{b}}(10 / 25)$ \\
\hline Bodily pain & $47^{\mathrm{a}}(35 / 72)$ & $30^{\mathrm{b}}(12 / 61)$ & $0^{c}(0 / 10)$ \\
\hline General health & $80^{\mathrm{a}}(50 / 90)$ & $70^{\mathrm{a}}(50 / 87)$ & $55^{\mathrm{a}}(45 / 67)$ \\
\hline Role limitation - emotional & $100^{\mathrm{a}}(33 / 100)$ & $100^{\mathrm{a}}(16 / 100)$ & $100^{\mathrm{a}}(100 / 100)$ \\
\hline Vitality & $65^{\mathrm{a}}(42 / 85)$ & $40^{\mathrm{b}}(30 / 65)$ & $80^{c}(55 / 90)$ \\
\hline Mental health & $60^{\mathrm{a}}(40 / 84)$ & $60^{\mathrm{a}}(28 / 74)$ & $60^{\mathrm{a}}(45 / 75)$ \\
\hline Social functioning & $75^{\mathrm{a}}(37 / 100)$ & $25^{\mathrm{b}}(0 / 50)$ & $68^{\mathrm{a}}(52 / 74)$ \\
\hline
\end{tabular}

Values in a row with the same superscript letter do not differ statistically $(\mathrm{p}<0.05)$ at the $5 \%$ probability level according to the Friedman test with the Dunn's post-hoc test 
Table 3 - SF-36 scores (mean, SD) in patients with hip fractures at baseline and four month follow-up

\begin{tabular}{|c|c|c|c|c|c|c|}
\hline \multirow{2}{*}{ Scales } & \multicolumn{2}{|c|}{ Baseline } & \multirow{2}{*}{$\mathrm{p}_{\text {value }}$} & \multicolumn{2}{|c|}{ Four month } & \multirow{2}{*}{$\mathrm{p}_{\text {value }}$} \\
\hline & FNF & TF & & FN & $\mathrm{T}$ & \\
\hline$\overline{\mathrm{PH}}$ & $58,8 \pm 28,56$ & $55,2 \pm 30,96$ & 0,35 & $19,9 \pm 20,06$ & $21,2 \pm 16,27$ & 0,40 \\
\hline RP & $49,8 \pm 42,01$ & $48,2 \pm 45,05$ & 0,49 & 0 & 0 & - \\
\hline BP & $51,0 \pm 21,79$ & $54,8 \pm 24,98$ & 0,19 & $14,7 \pm 24,77$ & $49,6 \pm 26,07$ & 0,12 \\
\hline GH & $65,5 \pm 26,06$ & $70,2 \pm 26,39$ & 0,28 & $71,6 \pm 22,73$ & $73,3 \pm 18,95$ & 0,41 \\
\hline VT & $51,0 \pm 21,79$ & $45,9 \pm 24,78$ & 0,23 & $87,5 \pm 26,54$ & $98,4 \pm 7,27$ & 0,32 \\
\hline $\mathrm{RE}$ & $73,5 \pm 40,51$ & $68,8 \pm 41,02$ & 0,44 & $60,7 \pm 21,19$ & $58,1 \pm 17,78$ & 0,65 \\
\hline MH & $57,1 \pm 27,89$ & $58,4 \pm 24,96$ & 0,46 & $64,3 \pm 18,99$ & $65,3 \pm 18,43$ & 0,42 \\
\hline SF & $65,9 \pm 31,81$ & $62,0 \pm 30,53$ & 0,34 & $66,6 \pm 29,91$ & $71,7 \pm 20,67$ & 0,51 \\
\hline
\end{tabular}

$\mathrm{PH}=$ Physical functioning; RP = Role limitation-physical; $\mathrm{BP}=$ Bodily pain; $\mathrm{GH}=$ General Health; $\mathrm{VT}=$ Vitality; RE = Role Limitation-emotional; $\mathrm{MH}$ $=$ Mental Health; $\mathrm{SF}=$ Social Functioning

Table 4 - SF-36 scores (median) in patients with undisplaced and displaced FNF at baseline and four month follow-up

\begin{tabular}{|c|c|c|c|c|c|c|}
\hline \multirow[t]{2}{*}{ Scales } & \multicolumn{2}{|c|}{ Baseline } & \multirow{2}{*}{$\mathrm{p}_{\text {value }}$} & \multicolumn{2}{|c|}{ Four month } & \multirow{2}{*}{$\mathrm{p}_{\text {value }}$} \\
\hline & displaced & undisplaced & & displaced & undisplaced & \\
\hline Physical functioning & 67.5 & 60 & 0.42 & 10 & 20 & 0.08 \\
\hline $\begin{array}{l}\text { Role limitation, } \\
\text { physical }\end{array}$ & 25 & 75 & 0.12 & 0 & 0 & - \\
\hline Bodily pain & 41.5 & 46.5 & 0.35 & 41.5 & 52 & 0.12 \\
\hline General health & 64.5 & 76 & 0.23 & 72 & 82 & 0.45 \\
\hline $\begin{array}{l}\text { Role limitation, } \\
\text { emotional }\end{array}$ & 100 & 100 & 0.29 & 100 & 100 & 0,31 \\
\hline Vitality & 41.5 & 46.5 & 0.35 & 51.5 & 72.5 & 0.02 \\
\hline Mental health & 48 & 62 & 0.17 & 58 & 68 & 0.05 \\
\hline Social functioning & 48 & 81 & 0.05 & 76 & 75 & 0.29 \\
\hline
\end{tabular}

$(-)=$ score equal to zero

Table 5 - SF-36 scores (median) in patients with unstable and stable TF at baseline and four month follow-up

\begin{tabular}{|c|c|c|c|c|c|c|}
\hline \multirow[t]{2}{*}{ Scales } & \multicolumn{2}{|c|}{ Baseline } & \multirow{2}{*}{$\mathrm{p}_{\text {value }}$} & \multicolumn{2}{|c|}{ Four month } & \multirow{2}{*}{$\mathrm{p}_{\text {value }}$} \\
\hline & Unstable & stable & & Unstable & stable & \\
\hline Physical functioning & 45 & 80 & 0.008 & 17.5 & 15 & 20 \\
\hline $\begin{array}{l}\text { Role limitation, } \\
\text { physical }\end{array}$ & 50 & 25 & 0.44 & 0 & 0 & - \\
\hline Bodily pain & 32 & 41 & 0.21 & 52 & 41 & 0.26 \\
\hline General health & 77 & 72 & 0.32 & 74.5 & 82 & 0.47 \\
\hline $\begin{array}{l}\text { Role limitation, } \\
\text { emotional }\end{array}$ & 83 & 100 & 0.39 & 100 & 100 & 0.37 \\
\hline Vitalit & 32 & 52 & 0.18 & 60 & 60 & 0.46 \\
\hline Mental health & 52 & 56 & 0.29 & 66 & 68 & 0.47 \\
\hline Social functioning & 68.5 & 72 & 0.37 & 75 & 75 & 0.12 \\
\hline
\end{tabular}

$(-)=$ score equal to zero

of hip fracture has on HRQOL. As in several previous studies, this study documented a significant deterioration of physical and psychosocial dimensions of the HRQOL in elderly subjects between the first and fourth months after hip fracture, with a partial recovery at the end of the fourth month. However, this observed impairment of the perceived well-being of the patient did not differ significantly between patients with femoral neck versus trochanteric fractures.

Several studies have previously indicated significant improvements over the period from three to six months after hospital discharge in functional capacity, the ability to perform activities of daily living, and for most dimensions of the HRQOL of elderly patients with uneventful surgical intervention and adequate rehabilitation following a hip 
fracture. ${ }^{17,18}$ However, hip fracture patients do not regain their pre-fracture well-being and functional level until one to two years after the fracture. ${ }^{3}$ Half of the previously independent patients become partly dependent, and one third became totally dependent after the injury. ${ }^{17,24}$ The effects of hip fractures on the mortality rate, the activities of daily life, and the quality of life can be even more devastating in elderly individuals who live under unfavorable socioeconomic conditions, like our patients. In our study, the observed mortality rate of nearly $30 \%$ four months after fracture was higher than expected (20\%) according to previous studies. . $^{17,23,28}$

The negative impact on the HRQOL observed in our patients can guide programs for the rehabilitation and health care of elderly people with a hip fracture. Family caretakers and professionals must recognize not only the physical, but also the psychosocial repercussions on the elderly with a hip fracture. Physical rehabilitation programs and emotional and social support must be provided early. Several factors appear to influence the magnitude of the functional compromise of patients after hip fracture: cognitive or neurologic impairment, infections, bone mineral density, body mass index, age, and pre-fracture functional state.

No previous studies have been conducted that compare the HRQOL in these types of fractures. In general, patients with trochanteric fractures have a poorer functional prognosis compared with those with femoral neck fractures, ${ }^{23}$ whereas the elderly with femoral neck fractures exhibit earlier functional rehabilitation than those with other types of fractures. ${ }^{23,28}$

Our results indicate that FNF had a similar impact on the HRQOL to TCF. These results may seem unexpected. Two factors can explain our findings. First, besides the type of fracture, several factors appear to influence the magnitude of compromised function, such as: cognitive or neurologic impairment, infections, bone mineral density, body mass index, age and pre-fracture functional state. Di Monaco et al. ${ }^{24}$ found that women with a FT have worse functionality than those with a FNF. However, these are dependent variables, since this finding disappears when these confounding factors are adjusted by multivariate analysis.

Second, a linear correlation does not necessarily exist between functional capacity and quality of life. Functionality is an objective measure of evolution (outcome), and depends on the evaluation and perspective of health care professionals. However, quality of life refers to the perception of patients regarding their physical and psychosocial states. It is possible that objective measures of physical function will not correspond, or will not be sufficiently different to have repercussions on the quality of life. The perception of well-being and the fulfillment of desires depend on a complex network of factors in which, for instance, mental function and family and social support may be more relevant than physical function.

Further studies should be performed with a larger number of patients and a longer follow-up time to clarify whether there is indeed any difference in quality of life according to the type of hip fracture in the elderly.

Our study showed that there were no significant differences in the HRQOL burden after comparing patients with unstable/stable TFs and undisplaced/displaced FNFs, although patients with a displaced FNF had better SF-36 scores on the "vitality" scale. Tidermark ${ }^{18}$ reported that undisclosed FNF patients scored significantly better on the HRQOL as measured by the EuroQol compared to those with a displaced FNF. These results cannot be compared to those in our study since all the patients studied by Tidermark were treated with internal fixation, while our patients with undisclosed FNF were treated with internal fixation and those with disclosed FNF were treated with total hip replacement.

A prospective randomized study compared dislocated hip fractures treated with internal fixation and total hip replacement ${ }^{3}$. In this study, the patients treated with total hip replacement had fewer surgical complications, reported less pain, and had a better walking ability at a four month follow-up than patients treated with internal fixation. In the same study, the patients treated with total hip replacement had better SF-36 scores for bodily pain and vitality scales. It should be noted that the current study also found that patients who were treated with total hip replacement also scored better on the vitality scale. ${ }^{3}$

Our study has some potential limitations. First, the HRQOL was assessed in a relatively small number of patients. This was due to exclusion of subjects with cognitive impairment and to the high mortality rate at the four month follow-up. We did not take into account factors such as income, the number of co-morbidities, pre-fracture health perception, post-fracture social support, or post-fracture function, all of which could influence the magnitude of the burden of hip fractures on the HRQOL (i.e. post-fracture health perception) of our patients. Understanding which variables are the most critical for HRQOL should help to improve treatment and rehabilitation programs for these patients.

The study strengths included the prospective evaluation of consecutive patients with hip fractures from a single area in a developing country, and the fact that, to our knowledge, this study is the first to assess the effects on the HRQOL of a particular type of hip fracture.

A few methodological difficulties are inherent in evaluating the quality of life in the elderly. Understanding the questions contained in the questionnaires and the 
reliability of the answers may be impaired by the presence of aggravated cognitive alterations, in the case of hip fractures, or by the experience of pain, anxiety because of inevitable hospitalization, restricted mobility, or the loss of autonomy. Furthermore, unfortunately the frequency of old people who are illiterate in Brazil is high, and $40 \%$ of our patients were illiterate. In order to reduce the interference of these factors on the quality of the results presented in this study, patients with a severe cognitive deficit were excluded, and the questionnaires were applied using an interview technique carried out by a single researcher. It should be pointed out that the instrument generally proved to be adequately reliable (Cronbach's alpha coefficient above 0.7).

The SF-36 used in the present study is a generic questionnaire for evaluating HRQOL and, therefore, does not address specific aspects of physical and psychosocial functioning. Specific quality of life instruments aimed at the elderly can yield more meaningful data concerning the degree of compromise in physical function. Unfortunately, a validated specific quality of life instrument in the elderly is not yet available for use in the Brazilian population.

Despite the limitations indicated, this study has clinical implications. Rehabilitation programs should offer objective conditions, with the goals of both recovering functional capacity and following the mental health of the elderly, independent of the type and severity of the hip fracture. Longitudinal studies with a longer follow-up time, along with generic and specific use of instruments for the elderly, are needed to evaluate the impact of hip fractures and the type of fracture on the HRQOL.

\section{REFERENCES}

1. Sambrook P, Cooper C Osteoporosis. Lancet. 2006; 367:2010-18.

2. Kanis J, Borgstrom F, De Laet C, Johansson H, Johnell O, Jonsson B, et al. Assessment of fracture risk. Osteoporos Int. 2005;16:581-9.

3. Tidermark J. Quality of life and femoral neck fractures. Acta Orthop Scand. 2003; 309:1-42.

4. Cooper C, Campion G, Melton LJ Hip fractures in the elderly: a worldwide projection. Osteoporos Int .1992; 2:285-9.

5. Rogmark C, Carlsson A, Johnell O, Sernbo I. A prospective randomised trial of internal fixation versus arthroplasty for displaced fractures of the neck of the femur: Functional outcome for 450 patients at two years. J B Joint Surg Br. 2002; 84:183-8.

6. Magaziner J, Simonsick EM, Kashner TM, Hebel JR, Kenzora JE. Predictors of functional recovery one year following hospital discharge for hip fracture: a prospective study. J Gerontol. 1990;45:101-7.

7. Koval KJ, Skovron ML, Polatsch D, Aharonoff GB, Zuckerman JD. Dependency after hip fracture in geriatric patients: a study of predictive factors. J Othop Trauma. 1996;10:531-5.

8. Suriyawongpaisal P, Chariyalertsak S, Wanvarie S. Quality of life and functional status of patients with hip fractures in Thailand. Southeast Asian J Trop Med Public Health .2003;34:427-32.

9. Hall SE, Williams JA, Senior JA, Goldswain PR, Criddle RA. Hip fracture outcomes: quality of life and functional status in older adults living in the community. Aust N Z J. 2000;30:327-32.

10. Jaglal S, Lakhani Z, Schatzker J. Reliability, validity, and responsiveness of the lower extremity measure for patients with a hip fracture. J Bone Joint Surg Am. 2000; 82:955-62.

11. Randell AG, Nguyen TV, Bhalerao N, Silverman SL, Sambrook PN, Eisman JA. Deterioration in quality of life following hip fracture: a prospective study. Osteoporos Int. 2000;11:460-6.

12. Peterson MG, Allegrante JP, Cornell CN, Mackenzie CR, Robbins L, Horton R, et al. Measuring recovery after a hip fracture using the SF-36 and Cummings scales. Osteoporos Int. 2002 13:296-302.

13. Jongjit J, Komsopapong L, Songjakkaew P. Health-related quality of life after hip fracture in the elderly community-dwelling. Southeast Asian J Trop Med Public Health. 2003;34:670-4.

14. Shyu Y I, Chen MC, Liang J, Lu JF, Wu CC, Su JY. Changes in quality of life among elderly patients with hip fracture in Taiwan. Osteoporos Int. 2003; 15:95-102.

15. Shyu YI, Lu JF, Liang J. Evaluation of medical outcomes study short form-36 Taiwan version in assessing elderly patients with hip fracture. Osteoporos Int. 2004;15:575-82.

16. Hallberg I, Rosenqvist AM, Kartous L, Löfman O, Wahlström O, Toss G. Health-related quality of life after osteoporotic fractures. Osteoporos Int. $2004 ; 15: 834-41$
17. Van Balen R, Steyerberg EW, Polder JJ, Ribbers TL, Habbema JD, Cools HJ. Hip fracture in elderly patients: outcomes for function, quality of life, and type of residence. Clin Orthop Relat Res. 2001;390:232-43.

18. Tidermark J, Zethraeus N, Svensson O, Törnkvist H, Ponzer S. Femoral neck fractures in the elderly: Functional outcome and quality of life according to EuroQol. Qual Life Res. 2002;11:473-8.

19. Salked G, Cameron ID, Cumming RG, Easter S, Seymour J, Kurrele SE, et al. Quality of life related to fear of falling and hip fracture in older women: a time trade off study. BMJ. 2000;320:341-6.

20. Boonen S, Autier P, Barette M, Vanderschueren D, Lips P, Haentjens P. Functional outcome and quality of life following hip fracture in elderly women: a prospective controlled study. Osteoporos Int. 2004;15:87-4.

21. Crotty M, Whitehead, C, Miller M, Gray S. Patient and caregiver outcomes 12 months after home-based therapy for hip fracture: a randomized controlled trial. Arch Phys Med Rehabil. 2003;84:12379.

22. Marks R, Allegrant JP, Ronald Mackenzie C, Lane JM. Hip fractures among the elderly: causes, consequences and control. Ageing Res Rev. 2003;2:57-93.

23. Koval KJ, Aharonoff GB, Rokito AS, Lyon T, Zuckerman JD. Patients with femoral neck and intertrochanteric fractures. Are they the same? Clin Orthop Relat Res. 1996;330:166-72.

24. Di Monaco M, Vallero F, Di Monaco R, Tappero R, Cavanna A. Hipfracture type does not affect the functional outcome after acute in-patient rehabilitation, a study of 684 elderly women. Eura Medicophys. 2007; 43:439-44.

25. Bertolucci PHF, Brucki SMD, Campacci SR et al. O mini-exame do estado mental em uma população geral: impacto da escolaridade. [The Mini-Mental State Examination in a general population: impact of educational status]. Arq Neuropsiquiatr. 1994;52:1-7.

26. Ciconelli RM, Ferraz MB, Santos W, Meinão I, Quaresma MR. Tradução para a língua portuguesa e validação do questionário genérico de avaliação de qualidade de vida SF-36 (Brasil SF-36). [BrazilianPortuguese version of the SF-36. A reliable and valid quality of life outcome measure]. Rev Bras Reumatol. 1999;39:143-50 [article in Portuguese].

27. McHorney CA, Ware JE Jr, Lu JF, Sherbourne CD. The MOS 36-item short form health survey (SF-36): III. Test of data quality, scaling assumptions and reliability across diverse patient groups. Med Care. 1994:32:40-66.

28. Willig R, Keinanen-Keukaaniemi S, Jalovaara P. Mortality and quality of life after trochanteric hip fracture. Public Health. 2001;115:323-32. 